\title{
Management of Calcific metamorphosis by conventional Root Canal Treatment. A case report Mahmud K H ${ }^{1}$, Iqbal M. A. ${ }^{2}$, Talukder $\mathrm{FH}^{2}$
}

\section{AFFILIATION:}

1. Dr. Kazi Hossain Mahmud

Assistant Professor, Dept. of Conservative Dentistry \& Endodontics, Update Dental College and Hospital. Dhaka, Bangladesh

2. Dr. Md. Ashif Iqbal

Associate Professor, Dept. of Periodontology \& Oral Pathology, Update Dental College and Hospital. Dhaka, Bangladesh

3. Dr. Fida Hasan Talukder

Assistant Professor, Dept of Conservative Dentistry \& Endodontics, Shere Bangla Medical College, Barishal, Bangladesh

\section{Article info.}

Received: 02 June 2020

Accepted: 08 August 2020

Volume: Vol-10, Issue-2, October 2020

DOI:

https://doi.org/10.3329/updcj.v10i2.50177

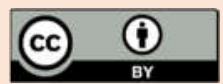

(C) Authors retain copyright and grant the journal right of first publication with the work simultaneously licensed under Creative Commons Attribution License CC - BY 4.0 that allows others to share the work with an acknowledgment of the work's authorship and initial publication in this journal.

https://creativecommons.org/licenses/by/4.0/

Publisher: Update Dental College, Dhaka, Bangladesh

Web: www.updatedentalcollege.edu.bd

E-mail: updcj@hotmail.com

\author{
* Corresponding Author \\ Dr. Kazi Hossain Mahmud, \\ Assistant Professor, \\ Department of Conservative Dentistry \& Endodontics \\ Update Dental College and Hospital , \\ Dhaka, Bangladesh \\ E-mail: kazimahmud007@gmail.com \\ Mobile: +88 01712260124
}

\section{Citation}

Mahmud K H, Iqbal M. A., Talukder F H, Management of Calcific metamorphosis by conventional Root Canal Treatment. A case report, UpDCJ; 10(2): 21-25 DOI: https://doi.org/10.3329/updcj.v10i2.50177

\begin{abstract}
:
The calcified root canals cause many problems during endodontic treatment due to difficulty in canal orifice location, negotiation, preparation as well as consideration of operating time. Most serious problem may arise during any phase of root canal treatment procedure even taking a lot of precaution. Partial or total obliteration of pulpal chamber or root canal space is the most common consequences of a tooth which is exposed to traumatic injury. The most common presentation of such a tooth is complete or partial loss of the pulp space radiographically and discoloration particularly yellow discoloration of the clinical crown. Around $7-27 \%$ of teeth having the feature of partial canal calcification shows features of pulp necrosis accompanied by radiographic signs of chronic periapical periodontitis. Very low numbers of teeth( 2-3\%) may present with total obliteration of pulp chamber and the root canal system . Teeth with such features is challenging to provide a successful root canal treatment; . In this case report a 21 years old female patient attended with complaints of discoloration, mild spontaneous pain , and several episodes of gingival swelling with history of trauma four years back in her both maxillary central incisors. The case was evaluated clinico radiographically and the diagnosis was a case of calcification both maxillary central incisors. Root canal treatment to manage the calcified canals following conventional technique was planned. After treatment patient was free from subjective and objective signs and symptoms and she was advised for periodic follow-up .
\end{abstract}

\section{KEY WARDS: Calcified canal, Root canal treatment, standardize technique}

\section{INTRODUCTION:}

generally root canal treatment is performed reduce or to completely remove or eliminate all the micro-organisms along with their byproducts from the root canal of the offending tooth ${ }^{(1)}$. To make the root canal system completely free from all kind of microorganisms and their west product we have to perform a standard mechanic-chemical debridement of the root canal system, proper disinfection followed by complete 3D obturation of the root canal system. But if the canal is narrow, blocked or obliterated by any biological calcific mass or any foreign particles, it became very difficult to gain the desired results ${ }^{(2)}$. Very often dental pulp tissues shows the features of dystrophic mineralization or calcific metamorphosis. Author around the globe usually defined Calcific metamorphosis as a response of pulp tissue to trauma which is usually characterized by deposition of hard and calcific tissue substances in the root canal system. This may happen as a results mineralization of pulpal soft tissues in response to any kind of irritants, aging process, traumatic injuries or sometimes idiopathically ${ }^{(3)}$. Sometimes this type of calcifications of the tooth can result complete or partial blockage of the access into the root canal systems and make the bio mechanical preparation, disinfection and obturation very tough sometimes impossible. Very often looking for the calcified root canal results an increased risk of perforation of the floor of pulp chamber, lateral wall, and root. ${ }^{(4)}$. In this 
case report we managed calcification in the maxillary central incisors following conventional technique.

Deposition of calcific hard tissue along the lateral wall of root canal is usually a very slow procedure, usually occurs in physiological aging process. After dental trauma, the incident of deposition of hard tissue rate is uncontrolled and results in Pulp Canal Obliteration (PCO) ${ }^{(5)}$. The clinical signs of PCO subsequent to a traumatic injury are often a yellowish discoloration and a gradual decrease of the response to thermal and electrical pulp testing when it is compared to adjacent normal teeth ${ }^{(5,6)}$. Bakland and Andreasen wrote that pulpal responses to traumatic injuries are affected by the degree of injury to the neurovascular supply, which for the most part enter through the apical foramen and also by the presence of bacteria as a significant role in the treatment outcome. Andreasen et.la concluded in their study that the possible outcomes of a traumatic injured tooth or teeth include healing of pulpal tissues, pulp necrosis, or pulp canal space obliteration. They reported that those changes or responses may result at different times, such as, initial healing may be followed by Pulp Canal Obliteration and subsequent necrosis of the pulp ${ }^{(7)}$. Patterson and Mitchell recommended either endodontic treatment or extraction of such tooth or teeth if they are identified clinically. They suggested that the pulp tissue which is involved in such conditions should be considered as a potential focus or source of infection and should be removed or treated ${ }^{(8)}$. Performing endodontic treatment in a calcified canals if indicated have several challenges for the operators or clinicians. The recent developments and advancement in endodontic armamentariums good quality imaging, high resolution magnification and newer instruments such as flexible rotary files helps in proper negotiation and managing the calcified canals correctly and efficiently without any procedural errors. In this case report we discussed the etiology, diagnosis and treatment options of the calcified canals so that it can help the clinician to understand this unpleasant clinical condition .

The clinicians around the globe studied about the calcification of the root canal system for several years. Calcification of the dental pulp may be two different type such as discrete and diffuse. Discrete type of calcification may occur in the form of formation of a dental pulp stones, denticles, or nodules. On the other hand diffuse type of canal calcification may be resulted in a symmetric reduction in the pulp chamber size of and also reduction of ridiculer pulp spaces and this is more commonly found in older patients then the youngers. Calcification of the dental pulp tissues may result in response to both local and /or systemic factors. Among the local factors responsible for pulpal calcifications include caries, cavity preparation, presence of large restorations particularly amalgum, and excessive occlusal force and trauma from occlusion or occlusal trauma. Systemic factors include hypocalcaemia, gout, and end-stage renal diseases.

The mechanism of calcific change of the pulp tissue resulting canal obliteration is not clear yeat. Torneck in 1990 suggested that the deposition of calcific hard tissue within the pulpal spaces may be a result is of stimulation of the pre- existing odontoblasts or as a result of losing their regulatory mechanism which contain a maze of small irregular spaces and cul-de-sacs. This procedure may extend from the pulp chamber towards the apical foramen. In the year of 1994 Andreasen and Andreasen 9 noted that calcific metamorphosis may occur as a response to severe injury to the pulpal neurovascular supply, which after healing may leads to accelerate the deposition of dentin, and is very closely related to the losing and regaining of the pulpal neural supply ${ }^{(10)}$. No mechanism have been proved histologically. There fore further evidence based research is necessary to prove the mentioned mechanism. It is already proven that the odontoblastic layer at the periphery of the pulp space and the undifferentiated mesenchymal cells of the pulp are capable to produce the osteoid tissue which is similar to dentin along the periphery of pulp chamber and/ or with in the pulp. Deposition of these type of tissue can be ultimately fuse along with one another, and may produce a rapid and complete obliteration pulp chamber and the root canal system ${ }^{(11)}$.

In the year of 1998 legendary oral biologist Ten Cate ${ }^{(12)}$ described this phenomena as deposition of tertiary or reparative dentin in response to irritation or trauma. Reparative odontoblastic cells are somehow capable of differentiating from dental pulp cells even in absence of any kind of epithelial influence. While the tooth is developed, the undifferentiated ectomesenchyme cell of the dental papilla divides into two different type of daughter cells. One daughter cell which is influenced by the epithelial cells a differentiates into an odontoblast and the other daughter cell which is not exposed to the epithelial influence remains as sub odontoblast cell. This cell layer often under certain influences can be differentiate into odontoblast-like cells and may results in deposition of dentin-like hard tissue ${ }^{(13)}$.

\section{CASE REPORT:}

Aa 21 years old female patient attended to the Department of Conservative Dentistry and Endodontics BSMMU,with complaints of discoloration, mild spontaneous pain, and several episodes of gingival swelling on her no 11 \& 21 teeth . She also gave a history of trauma four years back in those teeth. The case was evaluated clinico radiographically. On extra oral examination there was no abnormality, on intra oral examination there was discoloration of both maxillary central incisors and mild gingival swelling. On palpation the teeth were mild tender. On radiographic examination there was complete obliteration of the root canal system. And there was also the evidence of periapical bone destruction.

Diagnosis: Based on history, clinical and radiological findings the case was diagnosed as a case of calcification with chronic periapical periodontitis of both maxillary central incisors.

Treatment plan: Root canal treatment to manage the calcified canals following conventional technique was planned

Treatment procedure: After taking written consent from the patient, the total treatment procedure was explained to the patient. Possible merits and demerits was also explained to 
the patient. Then mouth preparation as done by scaling and polishing. Pre operative assessment was done by care full observation of the pre operative radiograph. A straight line access cavity was prepared for both of the teeth. Careful search of canal orifice was done with endodontic explorer at the expected location of the canal orifice. But it was calcified. Then it was decided to use a long shank carbide bur at low speed, carefully aligning it palatally to the long axis of the teeth and the calcified orifice was uncovered . then the canal were socked with $17 \%$ EDTA for five minutes. As there were a narrow catch, at this point a fine instrument No. 8 and No. $10 \mathrm{~K}$-file was placed into the catch, and an attempt is made to negotiate the canal. The cervical ledge or bulge was removed to provide straight line accesses to the orifice and the explorer was used to re-establish the canal orifice. After few attempt canals were negotiated up to the expected working length. Then working length was established by radio graphical method and it was $21 \mathrm{~mm}$ for both tooth no 11 and 21. After determining the working length canals were prepared following standardized technique upto no $45 \mathrm{k}$ file. Canals were irrigated with $5 \% \mathrm{NaOCl}$ for 5-10 minutes in between every change of instrument followed by normal saline. Then 17\% EDTA for 2 minutes. Final irrigation was done with $2 \%$ Chlorhexidine for $30-60$ seconds. $\mathrm{Ca}(\mathrm{OH})_{2}$ was placed mixed with equal amount of glycerin and distilled water for seven days and canal orifice were sealed with glass inomer cement..
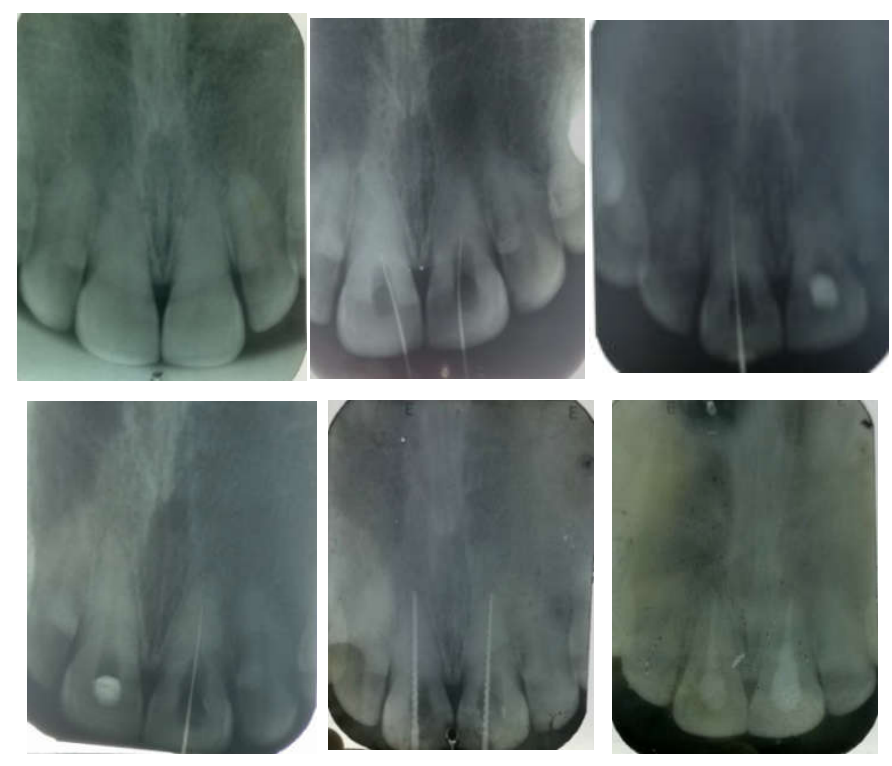

From upper left to right: fig-1: initial $x$-ray, fig-2: acesses preparation \& canal location, fig-3: $w / l$ of tooth no- 11 , fig-4: $w / l$ of toth no -21 , fig-5: pre obturation, fig-6: post obturation, [w/l: working length]

On the next appointment calcium hydro oxide was removed by copious irrigation of normal saline. Canals were socked with $5 \% \mathrm{NaOCl}$ for 5-10 minutes, ten 17\% EDTA for 2 minutes and final irrigation was done with 2\% Chlorhexidine for 30-60 seconds. Canals were dried with sterile paper point and obturatied using gutta parcha and calcium hydroxide containing sealer (Sealapex) following lateral condensation

23 | P a g e technique. After treatment patient was free from subjective and objective signs and symptoms and she was advised for periodic follow-up .

\section{DISCUSSION :}

The actual pathophysiology of pulpal tissue calcification is not known yet. There was opinion by several researcher that it may be due to transient incident of bleeding or hemorrhage followed by formation of blood clot in the pulp resulting from a traumatic injury might play the key roles for calcification, if pulp remains vital or recovers after the trauma. ${ }^{(14)}$ The nature, intensities, degree and frequencies of trauma also play an important role in pulp tissue calcification. In pulp tissue calcification the cellular components of pulp substances and therefor this may interfere with the blood flow to the pulp. In general around $4-24 \%$ of the teeth which are exposed to any kind of trauma, gradually develop different degrees of canal calcification which is characterized by the gradual loss of the pulp space when they are observed radiologically and also a gradual yellow discoloration of the crown ${ }^{(19,20,21)}$

Treatment of this kind of teeth should not completed if there is presence of any symptoms or radiographic evidence of any periapical disease ${ }^{(21,25)}$. If root canal treatment is needed in those teeth then they are considered as the high difficulty category according to the American Association of Endodontists Case Assessment criteria (17)

According to the guideline of AEA while preparing the access cavity of an anterior tooth with such pathology, the access cavity should be prepared close to or through the incisal edge. This technique provides the operator a straight-line access and avoid the chances of perforations or unnecessary damage (22). Usually in a tooth with normal physiology and anatomy, the pulp chamber is located at the center of tooth at the level of or near the Cemento Enamel Junctions ${ }^{(29)}$. In a tooth with calcific metamorphosis the pulp chamber becomes darker than that of the rest root dentine ${ }^{(29)}$. Therefore if the operator can maintain the access cavity preparation at the center, along the long axis of the tooth and limited to the level of the Cenento Enamel Jjunction, the root canal orifice is normally easily to located.

In recent years several studies have established that the use of a dental operating microscope in treating calcified canals improve a great deal regarding the outcome of treatment ${ }^{(30)}$. Different kinds of endodontic access cavity preparation burs and ultrasonic tips are available for deep toughing which is sometimes required to locate canals. Various type of dyes like, methylene blue may play an important role in identifying the root canal orifice of a calcific canal under the microscope. High concentration of Sodium hypochlorite $(5.5 \%)$ is also indicated to be used to identify calcified canals to perform the 'bubble' or 'champagne' test. When $5.5 \%$ sodium hypochlorite is placed in the pulp chamber over a calcified canal a stream of bubbles emerging from the oxygenation. This phenomena can be obsurved under the dental microscope and can used to determine the canal orifice ${ }^{(31)}$. while the access cavity is very deep it is recommended by the researchers to take intra oral radiographic from different angles so that clinicians can 
maintain the accurate alignment and proper direction of the root canals ${ }^{(24)}$

The scouting and negotiation of a narrow, curved and small calcified canals is always difficult and challenging. Usually Small number of initials files particularly No 6, 8 \& $10 \mathrm{~K}$-files are recommended for initial path finding. But the problem associated with these files are, they are lack of rigidity and can very often undergo fracture while using in vertical watchwinding motion with forces. To avoid such incident it is suggested that the clinicians should alternate between size 8 and $10 \mathrm{~K}$-files and use a gentle watch winding motion with minimal vertical pressure followed by regular replacement of the instruments before fatigue occurs. Different kinds of 'pathfinding' instruments are new addition now a days in endodontic treatment can perform this objective. These pathfinders or glide path instruments have multiple designs, but the most common feature is that all the instruments has quadrangular cross-section that has increased the rigidity of the files much higher then that of finishing files. ${ }^{(23)}$. Farther more chelating agents of different concentrations like $17 \%$ EDTA can be used as lubricant or to assist instrumentation after the negotiation of the root canal.

Among the different root canal preparation technique 'crown down' approach is suggested to follow to achieve remarkable tactile sensation, proper and better apical penetration. As a general guideline, the calcification process occurs in a coronoapical direction, so if the operator is able to get the initial canal captured, an instrument tends to progress more easily as it advances at the directions apical

canal terminus(22).

Schindler \& Gullickson concluded that periapical surgery or root-end resection and retrograde filling must be done when a canal cannot be located and endodontic treatment cannot be done up to the acceptable level. ${ }^{(25)}$ It is well established that endodontic microsurgery is a alternative treatment option of calcified canals when traditional root canal treatment fails because it provides a direct approach to the root apex ${ }^{(16,28)}$

\section{CONCLUSION}

A successful outcome of a root canal treatment depends upon several factors such as preparation of a proper access cavity, negotiation of root canal ,proper biomechanical preparation, disinfection of canal and finally 3D obturation. Proper clinical knowledge of tooth morphology, clinical experience, patience of the operators, using appropriate instruments and materials are also essential for successfully outcome of treatment in case of managing calcific metamorphosis. Application of advanced visualization and magnification technique along with conservative approach can be used to preserve natural the tooth structure. Unwanted incident of a procedural errors can happen if someone comets any kind of overzealous inappropriate attempts to locate the canals. Root wall or fraction perforations can occur even with most careful search. So clinicians should be aware of his or her margin of errors.

\section{REFERENCES:}

1. American Association of Endodontists. Glossary: Contemporary Terminology for Endodontics: AAE, 1998.

2. Yaacob HB, Hamid JA. Pulpal calcification in primary teeth: a light microscopy study. J Pedod. 1986;10(3):254-264.

3. McCabe PS, Dummer PM. Pulp canal obliteration: An endodontic diagnosis and treatment challenge. Int Endod J 2012;45(2):177-197. https://doi.org/10.1111/j.1365-2591.2011.01963.x PMid:21999441

4. Smith AJ. Dentine formation and repair. Chapter 3.In:Hargreaves KM, Goodis Heeds. Seltzer and Benders. Dental Pulp 2002. Berlin: Quintessence, pg

5. (Ngeow WC \& Thong YL. 1998. Gaining access through a calcified pulp chamber: a clinical challenge. IntEndod J, 31: 367-71.) https://doi.org/10.1046/j.1365-2591.1998.00176.x PMid:9823142

6. The Editorial Board of the Journal of Endodontics. 2008. Traumatic injuries: an online study guide. J Endod, May; $5 \mathrm{~S}$.

7. Schindler WG \&Gullickson DC. 1988. Rationale for the management of calcific metamorphosis secondary to traumatic injuries. J Endod, Aug; 14(8):408-12.

https://doi.org/10.1016/S0099-2399(88)80126-2

8. Patterson SS \& Mitchell DR. 1965. Calcific metamorphosis of the dental pulp. Oral Surg Oral Med Oral Pathol, 20: 94-101 https://doi.org/10.1016/0030-4220(65)90272-0

9. Andreason J, Andreason F. Textbook and colour atlas of traumatic injuries to teeth. 3 rd ed. Copenhagen, Munsksgaard; 1994

10. Amir FA, Gutmann JL, Witherspoon DE. Calcific metamorphosis: A challenge in endodontic Diagnosis and treatment. Quintessence Int 2001; 32(6):447-455.

11. Gopikrishna V, Parameswaram A, and Kandaswamy D. Criteria for management of calcific Metamorphosis: Review with a case report Indian J Dent Res. 2004;15(2):54-57.

12. TenCate AR. Oral Histology. Development, structure and function. 5th ed. St. Louis: Mosby;1998,pg 88-94.

13. Anderson AW, Sharav $Y$, Massler M. Reparative dentine formation and pulp morphology. Oral surg Oral Med Oral Pathol 1968;26(6):837-847 https://doi.org/10.1016/0030-4220(68)90358-7

14. Keijo luuko, Oaivi Kettunen, Inge Fristad \& Ellen berggreen. Structure \& function of dentin-pulp complex. Cohen's pathway of the pulp, tenth edition; $\quad$ pp. 452-503. https://doi.org/10.1016/B978-0-323-06489-7.00012-6

15. Endodontic Case Difficulty Assessment criteria; the American Association of Endodontist, 2010.

16. Shruti Saha, Ritu Prabha Patel, Pratibha Agrawal; Conservative Management of Calcified Canal with Maxillary Left Lateral Insicor: A Case Report; International Journal of Women Dentists 1(1):2014;49-51.

17. Tavares, Lopes, Menezes, Henriques, Ribeiro Sobrinho; non-surgical treatment of pulp canal obliteration using contemporary endodontic techniques: Case series; Dental Press Endod.,2(1),2012,52-58.

18. Modern Endodontic Access and Dentin Conservation, Part 2; Dentistry Today, www.dentistrytoday.com/endodontics. [8] Anna Akerblom,, and Gunnar Hasselgren; The Prognosis for Endodontic Treatment of Obliterated Root Canals; Journal Of Endodontics 1988. 14(11);565-567. https://doi.org/10.1016/S0099-2399(88)80092-X

19. Holcomb J, Gregory W Calcific metamorphosis of the pulp. Its incidence and treatment. Oral Surgery Oral Medicine Oral Pathology,24(12),1967,825-830.

https://doi.org/10.1016/0030-4220(67)90521-X

20. Robertson A, Andreasen F, Bergenholtz G, Andreasen J, Noren J, Incidence of pulp necrosis subsequent to pulp canal obliteration from trauma of permanent incisors. Journal of Endodontics 22(10),1996,557560 .

https://doi.org/10.1016/S0099-2399(96)80018-5 
21. Oginni AO, Adekoya-Sofowora CA, Kolawole KA, Evaluation of radiographs,clinical signs and symptoms associated with pulp canal obliteration: an aid to treatment decision. Endodontics and Dental Traumatology,25,620-625.

https://doi.org/10.1111/j.1600-9657.2009.00819.x PMid:19917027

22. McCabe $P$ Avoiding perforations in endodontics, Journal of the Irish Dental Association,52(3), 2006,139-48.

23. Allen MJ, Glickman GN, Griggs JA, Comparative analysis of endodontic pathfinders, Journal of Endodontics,33(6), 2007,723-726. https://doi.org/10.1016/i.joen.2007.02.001 PMid:17509414

24. O'Connor RP, DeMayo TJ, Roahen JO, The lateral radiograph: an aid to labiolingual position during treatment of calcified anterior teeth. Journal of $\quad$ Endodontics,20(4),1994, 183-184. https://doi.org/10.1016/S0099-2399(06)80332-8

25. Schindler WG, Gullickson DC, Rationale for the management of calcific metamorphosis secondary to traumatic injuries, Journal of Endodontics,14(8), 1988, 408-412. https://doi.org/10.1016/S0099-2399(88)80126-2

26. Selden HS, The role of the dental operating microscope in improved non surgical treatment of calcified canals, Oral Surgery Oral Medicine Oral Pathology, 68(7), 1989,93-98. https://doi.org/10.1016/0030-4220(89)90121-7

27. Ngeow WC, Thong YL, Gaining access through a calcified pulp chamber: a clinical challenge, International Endodontic Journal 31,1998,367-371. https://doi.org/10.1046/j.1365-2591.1998.00176.x PMid:9823142

28. Carrotte P, Surgical endodontics, British Dental Journal,198(2),2005,7179. https://doi.org/10.1038/sj.bdj.4811970 PMid:15702099

29. Krasner P, Rankow HJ, Anatomy of the pulp chamber floor.Journal of Endodontics $30(1), 2003,5-16$ https://doi.org/10.1097/00004770-200401000-00002 PMid:14760900

30. Gary B. Carr,Carlos A.F. Murgel,; The Use of the Operating Microscope in Endodontics; Dent Clin N Am,54,2010,191-214 https://doi.org/10.1016/j.cden.2010.01.002 PMid:20433974

31. Ruddle CJ,Identifying root canals endodontic strategies;Endodontic practice US;4(6);56. 